https://doi.org/10.48009/1_iis_2009_155-162

\title{
IMPROVING STUDENT EMPLOYABILITY BY EMBEDDING MARKETING CONCEPTS IN INFORMATION SCIENCE AND TECHNOLOGY COURSES
}

\author{
Cassandra C. Elrod, Ph.D., Missouri University of Science \& Technology, cassa@ mst.edu \\ Barry B. Flachsbart, Ph.D., Missouri University of Science \& Technology, barryf@mst.edu \\ William R. Kehr, Ph.D., Missouri University of Science \& Technology, wkehr@mst.edu
}

\begin{abstract}
The Department of Business and Information Technology at the Missouri University of Science \& Technology (Missouri S\&T), formerly the University of Missouri - Rolla, focuses on providing students with both business and information technology skill sets, particularly in its Information Science and Technology degree program. Students take business courses in addition to their technical courses, but it is believed that incorporating business concepts (especially marketing) directly into the technical courses will lead to better student retention of business and information technology concepts by the student. The goal is to meet employer desires and needs for new employees with a more rounded, holistic approach to business and information technology. Two courses taught at Missouri $S \& T$ are described herein which include this merging of concepts and which illustrate possible approaches to meeting the goal.
\end{abstract}

Keywords: Information Science, Marketing, Business Concepts, Information Technology, Higher Education, Student Employability

\section{INTRODUCTION}

In a society that is evolving into more and more dependence on technology in the business workplace, organizations with an array of business functions are becoming more reliant upon people who possess a sound understanding of technology and how it applies to their business [23]. Employees who can implement business and technology concepts simultaneously are becoming one of the most value added assets to companies, as suggested by the demand for new Information Technology hires [6]. Information gathering and manipulation is becoming more and more important to help organizations understand their customer markets and gather valuable market research from them to aid in the progress of their organization [17]. Reliance on technology-based methods for gathering information are becoming the norm, with the use of websites, databases, and other software applications [17]. Companies employing information handling

Volume X, No. 1, 2009 technologies need to understand and meet the requirements for competitive advantage through managerial involvement in hardware and software asset procurement that help in the strategy implementation process [21]. Given the emphasis on technology-based applications in organizations, the authors feel that it is extremely important for Information Technology graduates to understand business concepts, in particular marketing, both in order to increase their value as employees and to aid the organization, via integration of business practices and technology, in remaining competitive in a rapidly changing environment. Marketing educators have dealt with issues of including technology aspects into marketing subjects [1], but inclusion of business and marketing topics into technical courses has been explored less. This paper discusses the perspective of a merged department that houses both a Business and Management Systems degree as well as an Information Science Technology degree. Instructors are especially encouraged to consider all aspects of providing the integrated skill sets needed to manage technology.

\section{Degrees and Curricula at Missouri S\&T}

The degrees and curricula offered by the Business and Information Technology Department (BIT) at Missouri S\&T attempt to reflect industry demand, utilizing input from an Advisory Board of industry members, in-depth interactions with recruiters at Missouri S\&T Career Fairs, and feedback from graduating seniors as they begin employment.

Four degrees are offered within the department:

- B.S. in Information Science and Technology

- B.S. in Business and Management Systems

- M.S. in Information Science and Technology

- Masters in Business Administration (MBA)

Each B.S. degree program for students in BIT includes a set of core courses from the other B.S. major, along with courses in the primary major and general studies courses required by the University for all B.S. students. Specifically, undergraduate students in Business and Management Systems focus 
primarily on business topics, but they also take two courses that expose them to computer programming concepts; a course that deals with management information systems, including an introduction to database concepts; and one course that explores the technology and use of Enterprise Resource Planning systems in a business environment.

Undergraduate students in Information Science and Technology focus primarily on the use and applications of computing systems, but they also take common business topic courses including management and organizational behavior, financial accounting, corporate finance, and marketing.

The MBA degree utilizes enterprise resource planning technology and tools as a way of integrating the various business aspects of an organization.

Graduate students in Information Science and Technology are required to take a Leadership in Technology-Based Organizations course, which involves extensive discussions of business topics for technology organizations. Some MBA students also take the course as an approved elective; undergraduates in either B.S. major may also take this course as an option.

The Information Science and Technology undergraduate and graduate students are the principal interest in the present paper.

\section{RATIONALE}

Marketing educators have realized the value of teaching technology to marketing students and have addressed merging technology into marketing courses for some time. Initial efforts focused on including marketing information from technology-based sources [16], then using collaboration technology in classrooms [19]. Benbunan-Fich, et. al. [1] proposed a series of technological modules in order to meet a perceived need for today's managers to be "well versed in IT and able to communicate electronically with colleagues around the world, transfer data quickly, and keep in contact with customers." The use of instructional technology in specific courses was considered [7], and the use of IT in teaching marketing subjects was explored [8].

McBane [15] looked at both whether and how to teach marketing technology applications in the marketing classroom. After concluding that managers needed to understand technology as well as business theory, McBane noted the need for cooperation between technology employees and business/marketing employees: "For the general marketing student, exposure to the technology makes them aware of how technology can help them perform various marketing tasks, and can make it easier for them to interact with information technologists. Employees with an understanding of both technology and business processes are becoming valuable commodities. A new position is being created in many businesses today: the 'IT business analyst,' who works as a liaison between the IT department and the non-IT employees who have a business problem to solve." For a teaching academic department, such as the BIT department at Missouri S\&T, which includes both business and technical degree programs, McBane's words seem especially important. However, in addition to teaching technology topics to business/marketing students, there is also a need to teach marketing concepts to information technology students.

Missouri S\&T is putting forth a substantial effort in the Department of Business and Information Technology (BIT) to provide Information Technology students a sound business background, particularly with an integration of marketing concepts into several required courses, based on industry needs. It is believed that, if the education sector understands the industry sector need and required knowledge of students, then a successful flow through from student enrollment to industry employment can be achieved (See Figure 1) [4]. This cyclical process operates much like an inventory system and is particularly important to maintain enrollment standards and quality of the degree program. The process is a "pull system" in that industry is placing a demand, or need, for graduates and this causes the degree program to recruit students to meet the industry demand $[13,18]$. When this process is completed successfully, it is then repeated.

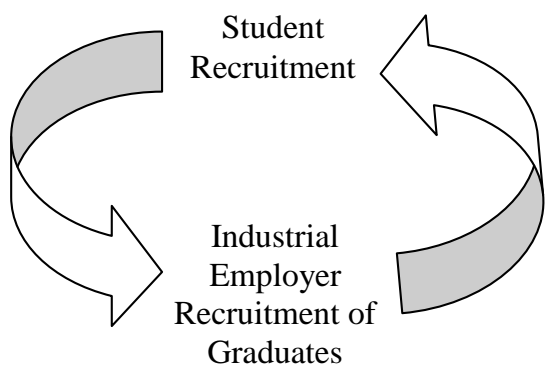

Figure 1: Cyclical Student to Industry Process 


\section{Example Courses at Missouri S\&T}

Two courses were chosen as examples putting business and marketing concepts into technology courses. The first, Computer Internals and Operating Systems [5], is an undergraduate class required of all Information Science and Technology B.S. majors. The second, Leadership in Technology-Based Organizations [10], is a graduate class required of all Information Science and Technology M.S. majors. It also may be taken by advanced undergraduate students.

\section{Course 1: Computer Internals and Operating Systems}

The goal of the computer internals and operating systems course is to help students understand more of the details about the technology. It deals extensively with computer architecture and the details of how various activities occur within computer systems, including details about the various hardware/software interfaces and the functioning of circuitry to actually carry out instructions in a computer. In addition to the technical information, however, there are many opportunities to discuss some of the interactions between technology and business topics, especially marketing.

\section{Clock Speeds}

One of the first opportunities comes during discussions about the "speed" of a personal computer (PC). One aspect is the speed of the internal "clock." This cycles on and off at a very fast rate, measured in Hertz (one cycle); a $3 \mathrm{GHz} \mathrm{PC}$ means that the internal clock cycles three billion times per second. The question that is raised is whether a $3 \mathrm{GHz} \mathrm{PC}$ is always better than a $2 \mathrm{GHz}$ PC. After discussions about the amount of work done in each cycle, students come to understand that a faster clock cycle is not necessarily better -- it depends on the amount of work done in each clock cycle. This is the point at which the marketing issue of "promotion" of a product can be introduced. Is a PC with a faster clock cycle easier to sell, even if it does not carry out as much real work in a period of time as a PC with a slower clock cycle? A simple concept is easier to promote, the class usually concludes.

\section{Critical Point: Business Issues and Technology} Issues BOTH Important!

After the discussion about clock speeds, students are told that "In this class, we will mostly discuss technical details, but we will also talk about business issues that arise from the technical details and that often matter much more than the technical details. We will see that getting the technical details wrong can mess up business decisions and that making inappropriate business decisions can make the technology irrelevant."

\section{PC History}

At about the mid point of the course, the class views a short series of videos (and has access to the transcripts of the videos) [2] that describe the early history of the personal computer and the personal computer industry. Although students learn a lot about the technical issues and breakthroughs that enabled the growth of the PC industry, the real point of these videos is to emphasize the business decisions that were made (or not made) and how they impacted the companies who made them. Many of these are basic business decisions, rather than marketing decisions, but they ultimately forced marketing approaches that were successful or not successful. Business opportunities missed or almost missed become quite clear in looking back. For example, the first video points out:

"Intel's microprocessors kept getting more powerful. By 1974 they came out with the 8080, which had enough horsepower to run a whole computer. Only Intel did not appreciate the brilliance of their own product, seeing it as useful mainly for powering calculators or traffic lights. Intel had all the elements necessary to invent the PC business, but they just did not get it."

The video then quotes Gordon Moore, one of the cofounders of Intel:

"Looking back I know of one opportunity where an engineer came to me with an idea for a computer that would be used in the home. Of course it was not yet called a personal computer. And while he felt very strongly about it, the only example of what it was good for that he could come up with was that a housewife could keep her recipes on it. And I could not imagine my wife with her recipes on a computer in the kitchen. It just did not seem like it had any practical application at all, so Intel did not pursue that idea."

The first personal computer, the Altair 8800, (really a kit) was developed by a company named MITS, owned by Ed Roberts. Their optimistic sales projection was that they could sell 800 of these, but within a month after the Altair 8800 was introduced, they were receiving 250 orders per month [2]! The point about missed sales projections provides an 
opportunity to have class discussions about business issues dealing with having more success than anticipated.

The Altair 8800 also caught the attention of two entrepreneurs: Bill Gates and Paul Allen. They realized that this PC would need software, something that was essential on the mainframe computers of the time, and they proposed to create a version of a programming language called BASIC for the Altair 8800. There is no denying the technical accomplishment of making this step for a PC, but the business understanding of the opportunity was really essential. Gates left his studies at Harvard and he and Allen founded a company which they named Microsoft. Class discussions about entrepreneurs and the passion that they often have for their inventions can be very helpful in again bringing out the need for business knowledge along with technical knowledge.

The first self-contained PC, the Apple II, was a big success, but expansion of sales beyond hobbyists required a "killer application" (killer app), an application that is so desirable that a person will purchase the PC just to be able to run that application [2]. The VisiCalc spreadsheet application provided such a killer app for the Apple II. This had been created from the vision of Dan Bricklin and the programming skills of Bob Frankstone at the Harvard Business School. Bricklin and Frankstone did not patent or otherwise protect their software. Class discussions about the concepts of patents and copyrights and the status of these in the late 1970s can bring out the need for being able to discuss business and technology issues with legal experts, normally requiring both business and technical skills.

The computer industry leader in 1980 was IBM, but IBM was focused on mainframes. In order to get into the growing PC marketplace quickly, they made some business decisions that later came back to haunt them. They elected to purchase almost everything from other vendors, but they allowed those vendors to market to others as well. Once IBM's proprietary BIOS was reverse engineered, so-called clone makers took IBM's pricing power from them. Class discussions here provide an opportunity to talk about the importance of retaining pricing power in order to meet business goals for profitability and about differing approaches for businesses with regard to costs and pricing.

\section{Early Visions Not Understood}

The most striking example of business executives not understanding the value of technical innovation is

Volume X, No. 1, 2009 that of Xerox and their Palo Alto Research Center (PARC). In the 1970s, Xerox PARC scientists made a number of striking breakthroughs: the computer mouse, the linkage of computers known as Ethernet, object-oriented programming, and a graphical user interface (GUI). But Xerox management did not understand what had been done or that it needed to be protected. Cringely [2] quotes various Xerox PARC scientists:

Larry Tesler: "But the brilliant researchers at PARC could never persuade the Xerox management that their vision was accurate. Head Office in New York ignored the revolutionary technologies they owned three thousand miles away. They just did not get it."

John Warnock: "None of the main body of the company was prepared to accept the answers. So there was a tremendous mismatch between the management and what the researchers were doing and these guys had never fantasized about what the future of the office was going to be and when it was presented to them they had no mechanisms for turning those ideas into real live products and that was really the frustrating part of it -- you were talking to people who did not understand the vision and yet the vision was getting created everyday within the Palo Alto Research Centre and there was no one to receive that vision."

The GUI developed at Xerox PARC became the foundation of the Apple Macintosh, and what was later created by Microsoft as Windows. The class discussion usually starts with asking: "How many people associate the Macintosh or Windows with Xerox"? Another start is to ask how many people know that the mouse was invented by Xerox. Or Ethernet? For these students, who understand a lot about the technical issues in each of these now wellknown computer technologies, this brings the point home very clearly about how important it is to be able to communicate technical information to business executives in terms the business executives will understand.

\section{Course 2: Leadership in Technology-Based Organizations}

The purpose of the leadership in technology-based organizations course is to impart knowledge and skills needed to manage and lead a technology-based organization in complex and competitive business environments. Areas of marketing theory discussed include diffusion of innovations, technological discontinuities, product life cycles, and market entry 
timing. Students are then given a number of assignments in which they apply some element(s) of the topic discussed to an actual operating company of their choice. Examples of companies that students have chosen include Siemens, EBay, Southwest Airlines, Caterpillar, Sprint, Medtronic, Boeing, Amazon, Trane, Coca Cola, Adtran, Maritz, Toyota, Anheuser-Busch, Valero Energy, and the Medical University of South Carolina.

Since information technology continues to experience an especially rapid rate of change, continuous learning is a cornerstone concept in the Information Science and Technology degree program. Yet, understanding technology without an understanding of marketplace interactions can leave students with a dangerously narrow and abbreviated view of the world in which technology is applied.

An example of the importance of dealing with changing technology and market forces is the telecommunications industry, which faces technology decisions that can spell survival or demise [9]. Business people make difficult choices, and bet their ability to serve the current needs of their customers on those choices. Students gain a better understanding of this industry and others in class discussions about marketing concepts and their application to real world applications. Some details of the class interactions are described below.

\section{Diffusion Theory}

Diffusion theory studies how new technologies are adopted over time [22]. "New" technologies may be either new to the market or improvements to existing technologies. Students have commented on new technologies and upgrades in discussions of industries such as semi-conductor manufacturing and healthcare. Adoption implies purchase and use, and becomes more important in highly competitive markets. Students often point to advancements in video games, encompassing both hardware and software innovations.

As markets react to increasing numbers of new technologies, the time for adoption becomes shorter [22]. Discussions in class have pointed to the decreasing amount of time taken for service providers to adopt new technologies, especially in the telecommunications industry. Consumer product manufacturers deal with the same problem. In assignments on this topic, students regularly give examples of quicker adoption of new consumer products and the need for rapid return on product development expenditures.
Technology adoption in organizations has different characteristics than adoption by individuals [22]. In organizations, groups work together seeking common goals through division of labor and regularized human relationships. In these situations, a process called "mutual adoption" frequently takes place [14]. Both the technology and the organization must change. Students have recognized that the increasing level of software employed in both products and processes can make this process less costly, increase customer satisfaction and speed integration new technologies.

\section{Technological Discontinuities}

Technological discontinuities are radical, discontinuous changes that may threaten the existence of entire industries [3]. Ehrnberg [3] suggests that the three dimensions of technological discontinuity are how it affects competencies and critical resources, the physical product or process involved, and its effects on the price/performance level. Competencies are discussed in the context of both leveraging existing competencies and allocating funds to build new competencies. Discussions of competencies include such applications as learning new medical testing techniques, the ability to integrate semiconductor innovations into existing product lines, and new production techniques to increase energy efficiency. Both the product and process can be technology driven. In assignments, students have proposed examples where new processes can reduce product costs, lead to new or improved service offerings, improve quality, and spawn new industries. Lastly, the relationship between price and performance is a major target of advancing technologies. The class has cited examples in the transportation sector where technologies have lowered costs and added quality and features.

In other cases, technological change may take place incrementally. Students have consistently noted the history of incremental changes in computer processors and price reductions in digital cameras. Where standards for new technologies and services are in flux, it is important for individuals with technology backgrounds to be involved in the standard development process.

\section{Product Life Cycles}

Technologies and products have finite lives and go through distinct stages, referred to as the product life cycle. Each stage of the cycle has its own opportunities and threats. Successful competitive strategy requires an understanding of this process and 
a clear knowledge of the place of each product or service offering in its life cycle [29].

In one view, products are seen as going through four stages [11]. In the Introduction stage, sales are slow, expenses are large, and profits are small. Students frequently discuss early e-commerce companies as examples of high payout and low revenues. Some companies are risk averse. One low risk alternative strategy at this stage is to become a technology supplier to an infant industry [26]. Students have suggested component manufacturers and hardware and service providers in industries such as logistics, telecommunications, e-commerce.

In the Growth stage, the market accepts the product, profits improve and competitors enter the market. In assignments, students often name other companies in the same or complementary industries. Diverse applications of technology can allow a risk averse company to launch new products to meet evolving market demands while taking advantage of an established customer base [27]. Students give examples of companies adding to their product lines to match or surpass competitors' offerings in terms of price, features and applications.

In the Maturity stage, sales growth slows because the product has saturated the market. Here the product generates the most income, but also serves a market that has been divided among the remaining players. Students point to the fact that the income can be used to fund research on new product offerings or to absorb competition. Students suggest alterations in content of consumables, or applying technology to add services or features. Here the insider's knowledge of the industry can provide insights into low risk applications of new or existing technology [28]. In assignments on the topic, students often point out strategies such as intra-industry alliances, seeking specialty markets, and developing new applications to sustain profitability.

In the Decline stage, sales and profit fall because of new and improved product offerings. Here class discussions center around specialty applications and niche markets for existing products. Students present examples of places where otherwise obsolete computer chips or medical devices are needed in certain special cases to sustain operations or treat patients. The low risk strategy is companies tapping their capabilities, knowledge, and skills to seek out profitable opportunities in new markets [25].

First Mover Advantages
The time when a company brings a new product to market can dramatically affect profits. The advantages of early entry are generally accepted. However, new technology or new applications of existing technology can let companies overcome the effects of market entry timing.

In assessing the impact of early market entry, [20] suggests advantages and disadvantages. Advantages include reputation, market position, switching costs, distribution channels, key suppliers, industry standards, barriers to imitation and early profits. Disadvantages include pioneering costs, uncertain demand, changed customer/user needs, irreversible capital investments, technological discontinuities, and low-cost imitations. Class discussions illustrate the fact that the elements of this set of pros and cons may apply to a wide variety of industries and product categories.

Kotler [11, 12] proposes 3 choices for companies bringing new products to market:

1) Being first in the market, taking advantage of supplier relationships, locking in key customers and gaining the reputation of technology leadership;

2) Entering the market in parallel with a competitor, where more attention is paid to two companies selling the same product; and,

3) Late market entry, where the late entrant takes advantage of prior market education and the ability to benefit from avoiding faults in the product offering of the first entrant.

Students point out how first entry can aid the company's reputation by being the first company that customers associate with a product or service. It is more difficult to convince students of the value of parallel entry. Late entry is more readily accepted. Students find many examples of companies who enhanced the features of a product or service and took market share away from first movers.

The fact that technology applications can overcome first mover advantages is particularly appealing to technology students. Shankar, Carpenter and Krisnamurthi [24] conducted a study of late entrants based on the level of innovation they applied. They found that products and services offered by innovative late entrants diffuse more quickly and have more repeat buyers than first-to-market companies. These effects are well documented by students in assignments based on the results of this study. 


\section{CONCLUSION}

The educator's job is not truly finished until former students enter the workforce as valuable assets to employers by implementing the knowledge gained from the educator. At that point, technical knowledge must confront the realities of commerce in a global marketplace. A comprehension of the interactions of business decisions with technical decisions and of the mechanisms through which products and services diffuse among consumers can help assure the success of organizations in today's rapidly changing environment The technologist's understanding of the interaction between market forces and technological change is essential to continued growth and profitability of affected organizations. Realistically, not all technologies are replaced as a result of innovations; realizing the finite lives of products and services that utilize established technologies informs students of other critical factors driving technological advancements. Lastly, an understanding of the complex relationships among technology development, product development, and market entry timing are be critical to the continued success and growth of modern enterprises. It is more clear than ever that incorrect business decisions can invalidate good technical decisions and that incorrect technical decisions can invalidate good business decisions -- understanding of both aspects is needed.

The discussions included here have illustrated ways of integrating business concepts into information technology courses that have been successful at Missouri S\&T. The approach used should be capable of being emulated for other technology courses at other institutions in order to assist students in retention of both kinds of topics and in realizing how important a balanced understanding is for career success.

\section{REFERENCES}

1. Benbunan-Fich, Raquel, Héctor R. Lozada, Stephen Pirog, Randi Priluck, and Joseph Wisenblit (2001), "Integrating Information Technology into the Marketing Curriculum: A Pragmatic Paradigm," Journal of Marketing Education. 23-1 (April), 5-15.

2. Cringely, Robert., X. (1996). Triumph of the Nerds: The Rise of Accidental Empires, Public Broadcasting System Television Special (http://www.pbs.org/nerds/tvdes.html).

3. Ehrnberg, Ellinor. (1995). "On the Definition and Measurement of Technological Discontinuities." Technovation 15: 437-452.

4. Elrod, Cassandra., C. (2007). The Development and Application of a Systematic Approach to
Evaluating an Academic Department's Brand Meaning. Engineering Management \& Systems Engineering. Rolla, University of Missouri Rolla. PhD: 87.

5. Flachsbart, Barry. (2008). Information Science \& Technology 231 Course Notes \& Lectures, Missouri University of Science \& Technology.

6. Freeman, Huey. (2008). "State Farm Actively Recruits Graduates with Tech Degrees." McClatchy - Tribune Business News Washington.

7. Hannaford, William, Robert Erffmeyer, and Chuck Tomkovick (2002), "Championing Technology in Marketing Education: Assessing the Value of a Discipline-Specific Technology Course," Marketing Education Review, 12-3 (Fall), 47-57.

8. Hunt, Lynn, Lynne Eagle, and Phillip J. Kitchen (2004), "Balancing Marketing Education and Information Technology: Matching Needs or Needing a Better Match?" Journal of Marketing Education, 26-1 (April), 75-88.

9. Kehr, William., R. (2002). A Study of Early Adopter of Technology in the Independent Telephone Industry. Engineering Managment. Rolla, University of Missouri - Rolla. PhD.

10. Kehr, William., R. (2008). Information Science \& Technology 351 Course Notes \& Lectures. Missouri University of Science \& Technology.

11. Kotler, Philip. (1997). Marketing Management Analysis, Planning, Implementation, and Control. New Jersey, Prentice Hall.

12. Kotler, Philip. (2000). Marketing Management The Millennium Edition, $10^{\text {th }}$ Editon. New Jersey, Prentice Hall.

13. Lee, Hsu-Tung, \& Michael H. Wang (2008). "On the Search of Workstations Arrangement in Pull Production Systems." Computers \& Industrial Engineering 54(3): 613-623.

14. Leonard-Barton, Dorothy. (1998). "Implementation as Mutual Adaption of Technology and Organization." Research Policy 17: 251-267.

15. McBane, Donald (2003), "Getting the Horse to Drink: Teaching Technology to Marketing Students," Marketing Education Review, 13-2 (Summer), 1-6.

16. Miller, Fred, and W. Glynn Mangold (1996), "Developing Information Technology Skills in the Marketing Curriculum," Marketing Education Review, 6-1 (Spring), 29-39.

17. Milne, George., Shalini Bahl, \& Andrew Rohm (2008). "Toward a Framework for Assessing Covert Marketing Practices." $\underline{\text { American }}$ Marketing Association 27(1): 57-62. 
18. Najarian, Gerald (2008). "The Pull System Mystery Explained: Drum, Buffer \& Rope With a Computer." Retrieved 5/2/2008, 2008, from http://www.themanager.org/Strategy/Pull_Syste m.htm.

19. Paul, Pallab and Kausiki Mukhopadhyay (2001), "Using Information Technology for Active Learning in International Business Education," Marketing Education Review, 11-3 (Fall), 81-89.

20. Porter, Michael (1985). Competitive Advantage: Creating and Sustaining Superior Performance. New York, The Free Press.

21. Porter, Michael \& Victor Millar (1985). "How Information Gives You Competitive Advantage." Harvard Business Review July 1: 12.

22. Rogers, Everett, M. (1995). Diffusion of Innovations. New York, The Free Press.

23. Savvas, Anthony. (2008). "IT Graduates Failing Firms On Continuity." Computer Weekly: 37.

24. Shankar, Venkatech, Gregory W. Carpenter, and Lakshman Krisnamurthi. "Late Mover Advantage: How Innovative Late Entrants Outsell Pioneers," Journal of Marketing Management, 35, February 1998, pp 54-70.

25. Unknown (1994). "Growth in a Declining Market." INC 500: 99.

26. Unknown (1994). "Growth in a Developing Market." INC 500: 93-94.

27. Unknown (1994). "Growth in a Growing Market." INC 500: 94 \& 96.

28. Unknown (1994). "Growth in a Mature Market." INC 500: 96 \& 98.

29. Wasson, Chester, R., (1974). Dynamic Competitive Strategy \& Product Life Cycles. St. Charles, IL, Challenge Books. 